\title{
Influence of composite preform fabrication on the integrity of poly-aryl-ether-ketone matrices
}

\author{
Olivier De Almeida ${ }^{1}$ () \\ Lisa Feuillerat ${ }^{1}$ \\ Vivien Nouri ${ }^{1,2}$ \\ Karim Choquet ${ }^{1}$
}

\author{
${ }^{1}$ Institut Clément Ader (ICA), Université \\ de Toulouse, CNRS UMR 5312, IMT \\ Mines Albi, UPS, INSA, ISAE-SUPAERO, \\ Campus Jarlard, Albi, France \\ ${ }^{2}$ Laboratoire des IMRCP, Université de \\ Toulouse, CNRS UMR 5623, Université \\ Toulouse III, Paul Sabatier, France \\ Correspondence \\ Olivier De Almeida, IMT Mines Albi, \\ Institut Clément Ader, Campus Jarlard, \\ Albi 81000, France. \\ Email: olivier.dealmeida@mines-albi.fr \\ Funding information \\ Region Occitanie
}

\begin{abstract}
Poly-Aryl-Ether-Ketones (PAEK) matrices of different composite preforms were evaluated to assess the influence of the preform manufacturing on the matrix integrity. Yarns, films, and impregnation suspensions were characterized by gel permeation chromatography, Fourier transform infrared spectroscopy, thermogravimetric analysis, differential scanning calorimetry, and rheometry. As described in literature, changes in the matrix properties at molten state are observed for all materials. The degradation process is related to a crosslinking process that results in an increase of viscosity and a decrease of crystallization temperature. Differences in degradation behavior were observed depending on the type of preform. Film and yarn extrusion has a limited effect on PAEK behavior, apart from a slight shift in molecular weight, without significant effect on degradation kinetics. However, the organic products that are used for the preparation of semifinished composite products, that is, yarn sizing or suspension additives, have a detrimental effect on stability. The degradation of additives considerably increases the degradation kinetics of the PAEK matrices, and by modifying the thermo-oxidation mechanisms, the advantages of using complex preforms for consolidation can be annihilated.
\end{abstract}

\section{K E Y W O R D S}

crystallization, degradation, molecular recognition, rheology, thermogravimetric analysis

\section{INTRODUCTION}

Thermoplastic matrix composites have undeniable advantages compared to thermosets for structural applications: higher toughness, higher service temperature, easier storage, weldability, recycling, and so on. In addition, the overall processing time for thermoplastic composite manufacturing can be significantly reduced compared to thermosets as the fabrication does not involve a crosslinking reaction. However, fully impregnating the reinforcement and obtaining a uniform dispersion of the fibers within the matrix remains an issue because of the high-melt viscosity of thermoplastics.
Many efforts have been made over the past decades to improve the processability of thermoplastic composites and different strategies have been explored to facilitate the fabrication of thermoplastic composites. One possible approach consists in modifying the polymeric matrices in order to decrease their viscosity and make them adapted to resin transfer molding. Thereby, promising results have been obtained with low-viscosity thermoplastics ${ }^{1}$ or with thermoplastic monomers, ${ }^{2,3}$ but these approaches are still limited to polymers with low-glass transition temperatures, whose properties are insufficient for satisfying the requirements of aerospace applications.

The main strategy used so far for the manufacturing of high-performance matrix composites consists in using 
semi-finished preforms in which the matrix is already distributed around and within the reinforcement before the final consolidation operation. In other words, since the polymer flow during consolidation under pressure is limited and does not allow a multi-ply preform to be directly impregnated, single ply preforms combining the reinforcement with the polymeric matrix under different forms have been developed. The consolidation of composite parts and laminates can then be achieved by thermo-compression molding using a hot press or an autoclave.

Various semi-finished products of different architectures have been proposed over the years in order to improve simultaneously the drapability, the preform handling, the mechanical performances and the impregnation behavior. ${ }^{4}$ Katsiropoulos et al. for instance proposed quadriaxial non-crimp fabrics (NCF) architectures in which the PEEK matrix is introduced in powder, fleece or filament form between or within the plies. ${ }^{5}$ The various thermoplastic semi-finished products can be categorized depending on the form of the polymeric matrix:

- Film: polymer films previously prepared by cast-film extrusion are placed between each ply of the dry fibrous preform. The use of films represents the most versatile approach for the fabrication of thermoplastic composites as the fiber volume fraction can be easily modified and any type of reinforcement can be used. ${ }^{6}$

- Powder: fine polymer powder is deposited on the reinforcement and then melted for ensuring the adhesion of the as-formed drops thanks to wetting effect. ${ }^{7}$ Infrared ovens are commonly used for melting the polymer, and because of the absence of a calendering unit that would homogenize the melt drops, the fibrous preform remains dry and relatively flexible.

- Filaments: polymer yarns are previously prepared by melt spinning and then combined with the reinforcement. In co-woven preforms, the spun yarns of matrix are woven with carbon tows. The resulting preform is a composite fabric in which warp and weft yarns can be the matrix and/or the reinforcement. In commingled preforms, before weaving operations, the polymer yarns are first combined with the reinforcement tows so as to obtain a yarn in which the filaments of both phases are mixed together. ${ }^{8}$ Micro-braiding is also an alternative organization of the polymer filaments around the reinforcing fibers. ${ }^{9}$

- Continuous phase: in pre-impregnated preforms, each single reinforcing ply or tow is initially impregnated. The reinforcement is thus embedded by a continuous matrix phase. Pre-impregnated preforms can be prepared using a slurry powder impregnation route, ${ }^{10,11} \mathrm{a}$ solvent process $^{12}$ or using a melt route with hot double-belt presses. ${ }^{13}$ A pre-impregnated product can also be obtained by using extrusion (pultrusion or DRIFT process). ${ }^{14,15}$ The final void content is already low after pre-impregnation, but in return, the resulting product is stiff which limits its drapeability.

Most of the literature describing the various thermoplastic composite preforms focuses on the impregnation behavior, and conclude about the improvement of preforms processability when using advanced semi-finished products combining both phases. ${ }^{4}$ However, only few articles effectively compare the processability of different preform architectures with the same matrix, and even fewer actually deal with high-performance thermoplastic matrices. ${ }^{16,17}$ The influence of polymer transformation from the raw pellet state to its final shape is therefore never considered, even though a transformation at the molten state is always required during the preparation of complex semi-finished products. Modification of polymers integrity after extrusion operation has already been reported for many polymers. ${ }^{18,19,20}$ For sensitive polymers, the transformation operations required for the fabrication of the preform may then have consequences on the consolidation behavior of thermoplastic composites.

Among the different matrices used for the fabrication of advanced composite preforms, high-performance composite matrices and in particular poly-aryl-ether-ketones (PAEK) polymers are known to be highly sensitive to thermal degradation because of their high glass and melting temperatures. Their thermal stability is indeed limited at elevated temperatures beyond the melting point, particularly in presence of oxygen. ${ }^{21,22,23,24}$ The chemical decomposition is initiated by the breakdown of ketone and ether bonds of the monomer unit, and lead to the formation of acyl, phenoxyl, and phenyl radicals species. Then during the thermal and thermo-oxidative aging of PAEK, further reactions of propagation occur to form hydroperoxides that lead to formation of different products: phenols, benzoic acid, and so on. Finally, the termination reactions involving inter- and intramolecular processes occur depending on the atmosphere and temperature. This leads to the formation of dibenzocyclopentanone and dibenzofurane derivatives that rapidly induce the crosslinking of PAEK molecules. ${ }^{25,26,27,28}$ The consequence of these chemical reactions is a modification of the molecular weight, ${ }^{26}$ but also modifications of the physical and mechanical properties like the crystallization behavior, melting and glass transition temperatures as well as modulus. $^{29,30,31,32}$ In particular, the crosslinking process results in a rapid increase of the polymer viscosity, ${ }^{30,32,33}$ which has a detrimental effect on the resin flow during the preform consolidation. Phillips et al. demonstrated for instance that the impregnation of a carbon reinforcement with PEEK films is 
strongly reduced after a heat treatment of a few seconds at $400^{\circ} \mathrm{C}^{34}$ Therefore, the probability that the properties of PAEK matrices are modified during the fabrication of composite preforms is not negligible.

The control of the thermal degradation of PAEK is even more critical since chemical additives are usually employed during the preparation of semi-finished composite products, like for instance the sizing applied on spun yarns for achieving cold drawing. The interaction of PEEK matrix with its surrounding chemical environment has indeed already been reported by Denault et al. ${ }^{16}$ They observed a change in the matrix behavior and fiber-matrix adhesion after composite manufacturing. In a patent dealing with the formulation of polymer suspensions for the slurry powder impregnation process, Arkema also mentions that the nature of the additives used for stabilizing PEKK suspensions as well as the carbon sizing have a critical effect on the thermal stability of the polymer. ${ }^{35}$ This aspect is thus of prime importance when designing innovative high-performance composite preforms.

This study thus aims at investigating the consequence of processing PAEK matrices for the fabrication of composite preforms. The effect of PAEK processing at the molten state is investigated by the comparison of the matrix after transformation with the same raw polymer. The influence of the chemical additives involved during the transformation operations is also analyzed but the interaction with carbon fiber sizing is not taken into account although it has also an influence on the evolution of PAEK properties. ${ }^{16,35}$ The carbon fiber sizing is designed to ensure a good bond at the fiber matrix interface, and can easily be applied on the fibers and tailored to the chosen matrix. Additives, on the other hand, are introduced in the system as a matter of processing necessities: without these the production of most preform would be impossible. It was therefore decided to focus this study on the effect of those additives.

Three thermoplastic composite preforms in which the matrix is in film or filament form and two aqueous formulations for slurry powder impregnation have been investigated. The chemical structure of the different matrices was characterized by means of gel permeation chromatography (GPC) and Fourier transform infrared spectroscopy (FTIR), and the kinetics of thermal and thermo-oxidative degradation of PEEK and PEKK were investigated using differential scanning calorimetry (DSC), thermogravimetric analysis (TGA) and rheometry. The contribution of both the transformation at the molten state and the presence of additives on the thermal stability of the composite matrices is analyzed by comparison with the raw polymer.

\section{EXPERIMENTAL}

\subsection{Materials}

\subsubsection{Commingled PEEK-carbon NCF}

The PEEK matrices of two composite products specifically developed for the purpose of the INMAT2 project (2008-2011) were evaluated in this study. Both composite products are quadriaxial NCF in which the carbon fibers were combined with PEEK filaments $(20 \mu \mathrm{m})$ within each ply. The same PEEK grade from Victrex (150G) was used for the preparation of both materials (PEEK 1).

The first NCF preform contains $64 \%$ of carbon and was manufactured by aligning $3 \mathrm{k}$ carbon tows with PEEK yarns so as to obtain unidirectional plies with an areal weight of $145 \mathrm{~g} \mathrm{~m}^{-2}$. The four plies of the NCF architecture were stitched together with a PEEK yarn which final areal weight in the NCF preform represents $5 \mathrm{~g} \mathrm{~m}^{-2}$. In this product, the method of aligning carbon and PEEK yarns resulted in a material of relatively poor commingling level but involving continuous reinforcement is each direction of the NCF. The aligned and stitching yarns removed from this NCF preform is hereafter referred as PEEK Yarn 1.

The second NCF also contains $64 \%$ of carbon fibers and the plies were also stitched with a PEEK yarn. Each ply of this product is $213 \mathrm{~g} \mathrm{~m}^{-2}$ and the amount of stitching yarn represents $60 \mathrm{~g} \mathrm{~m}^{-2}$. It mainly differs from the first NCF in that the plies were prepared from stretchbroken commingled yarns. This technique significantly improves the commingling level although breaking the carbon filaments reduces the mechanical performances of the final composite. The aligned and stitching yarns extracted from this second NCF preform are hereafter referred as PEEK Yarn 2.

The chemical nature of the sizing that was deposited at the surface of these yarns during the melt spinning operation was investigated. Sizing filtration of the filaments was achieved using a Soxhlet apparatus and the filtered sizing was then analyzed by FTIR. The comparison of the sizing absorption bands with a database of commonly used chemicals allowed identifying that an epoxybased sizing was sprayed on the PEEK Yarn 1 with a ratio of $0.45 \%$ while a sizing based on polyethylene glycol ester (PEG Ester) was applied at the surface of PEEK Yarn 2 with a ratio of $0.27 \%$.

\subsubsection{Stitched PEKK film stacked NCF}

The third composite product considered in this study was developed by Chomarat in 2019. It is also a quadriaxial 
non crimp fabric but composed of 4 plies of AS4 unidirectional carbon fibers stacked with 4 or 5 PEKK films of $25 \mu \mathrm{m}$ thickness. The PEKK film involved in this product was manufactured by cast film extrusion from the Arkema 7002 PEKK grade. The insertion of a film between each carbon ply of $67 \mathrm{~g} \mathrm{~m}^{-2}$ significantly improved the consolidation process compared to a conventional film-stacking route involving dry quadriaxial NCF preforms.

Two versions of this composite product were considered in this study, versions that only differ by the nature of the yarn used for assembling together the carbon plies and the PEKK films. The first one is a PEEK yarn of 50 dtex spun from Victrex $150 \mathrm{G}$ and the second one is a PET yarn of 76 dtex, hereafter referenced as PEEK Yarn S and PET Yarn S respectively. Since both NCF composite products were prepared using the same stitch, the stitching yarn represents $4.6 \mathrm{~g} \mathrm{~m}^{-2}$ and $3 \mathrm{~g} \mathrm{~m}^{-2}$ in the case of PEEK and PET respectively.

The thermal stability of the PEKK film was analyzed considering a configuration involving four layers of PEKK film in the composite preform (referred as PEKK Film). The mass ratio of stitching yarn to PEKK matrix were therefore $3.6 \%$ and $2.3 \%$ in the case of PEEK Yarn S and PET yarn $\mathrm{S}$ respectively.

\subsubsection{PEKK suspension for slurry powder impregnation}

The composition of PEKK suspensions used in the slurry powder impregnation process for the fabrication of preimpregnated ribbons was also analyzed in this study. In this process, pre-impregnation is achieved by soaking the fibers in an aqueous dispersion of polymer powder, and the impregnation efficiency and homogeneity are directly controlled by the formulation of the aqueous powder suspension. Suspension additives have a major role on the aqueous powder impregnation: they act as a polymeric dispersant and as a binder at the fiber-matrix interface. ${ }^{36}$ The stability of powder suspensions is generally obtained by adding a few percents of surfactants and other additives, but different stabilization approaches are also possible. Emulsions or hydrogels for instances can delay powder sedimentation, limit particles agglomeration and improve particles dispersion. ${ }^{37}$

Two PEKK suspension formulations that have been used for the manufacturing of carbon-PEKK preimpregnated ribbons were analyzed in this study. The composition of both formulations is $79.8 \%$ of water, $20 \%$ PEKK Kepstan 7002 PT provided by Arkema in powder form and $0.2 \%$ of additives. The first formulation contains a polymeric surfactant supplied by PROTEX under the reference PROX-MAT-PLC-711 P. This surfactant is a sodium polynaphthylmethane sulfonate supplied in the form of a dry powder. The second formulation is a nanoemulsion prepared with two surfactants and an oil. The oil used in the suspension is a tributyl citrate, and the surfactants are a Polyoxyethylene (4) lauryl ether from Sigma Aldrich supplied under the reference Brij L4 and a polyoxyl hydrogenated castor oil also provided by Sigma Aldrich as the reference Kolliphor RH40. The proportion of additives in the nano-emulsion was $22 \%$ of Brij L4, $45 \%$ of Kolliphor RH40 and $33 \%$ of tributyl citrate. The raw PEKK powder and the two combinations of PEKK and additives are hereafter respectively designated PEKK, PEKK+Add1, and PEKK+Add2.

In order to analyze the influence of these additives on PEKK integrity, the suspensions were dried at $70^{\circ} \mathrm{C}$ overnight. The final additives to PEKK ratio was thus $1 \%$ for both formulations. This ratio corresponds to the matrix composition in the oven of the preform manufacturing process before melting.

\subsubsection{Raw materials}

The PEEK and PEKK matrices of preforms and suspensions were compared to the same raw materials in powder form. For comparison of PEEK matrices, two references of Victrex $150 \mathrm{P}$ were used. Since the commingled NCF preforms were manufactured in 2009, the analysis of PEEK Yarn 1 and PEEK Yarn 2 properties has been carried out by comparison with a PEEK Victrex 150P from the same period. This PEEK powder is referenced PEEK 1 hereafter. The properties of the PEEK Yarn S used to stitch the PEKK films with the unidirectional carbon plies has been compared to data recorded on a recently supplied PEEK 150P from Victrex. This new generation PEEK 150P, referenced hereafter PEEK 2, differs slightly from the previous generation. Finally, the PEKK reference used for comparison with the PEKK suspensions and film was simply the same PEKK Kepstan 7002 PT powder used to prepare the powder suspensions. For clarity, Table 1 summarizes all investigated materials, their corresponding nomenclature and related raw polymer used for comparison.

\subsection{Methods}

\subsubsection{Gel permeation chromatography}

GPC characterization was performed on all PEEK and PEKK products, and PET. Measurements were performed by PEAKEXPERT Company on a Waters 2695 device with a Waters 2414 RID detector. The separation was carried out at $35^{\circ} \mathrm{C}$ within two Mixed-D Agilent GPC 
TA B LE 1 Nomenclature of studied materials and corresponding raw material

\begin{tabular}{|llllll}
\hline Composite matrix & & & Corresponding raw material \\
\cline { 1 - 2 } Description & Designation & & Description & Designation \\
\hline PEEK Yarn from 1st commingled NCF & PEEK Yarn 1 & & PEEK 150P (Ref 2009) & PEEK 1 \\
PEEK Yarn from 2nd commingled NCF & PEEK Yarn 2 & PEEK 150P (Ref 2009) & PEEK 1 \\
PEKK with additives 1 & PEKK+Add1 & PEKK+Add2 & & PEKK 7002 PT & PEKK \\
\hline PEKK with additives 2 & PEKK Film & & PEKK 7002 PT & PEKK \\
\hline PEKK film & PEEK yarn S & & PEEK 150P (Ref 2019) & PEEK 2 \\
\hline PEEK stitching yarn & & & & \\
\hline
\end{tabular}

Abbreviation: NCF, Non-Crimp Fabric.

columns from Agilent, with $5 \mu \mathrm{m}$ particle size, $7.5 \mathrm{~mm}$ internal diameter and 50 and $300 \mathrm{~mm}$ length, respectively. The eluent was dichloromethane/dichloroacetic acid with $0.01 \mathrm{M}$ of tetrabutylammonium acetate at a

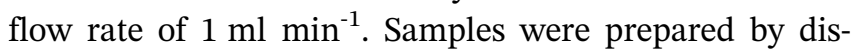
solving $20 \mathrm{mg}$ in $10 \mathrm{ml}$ of eluent during $8 \mathrm{~h}$ and filtering using filters with $0.45 \mu \mathrm{m}$ pore size.

\subsubsection{Fourier transform infrared spectroscopy}

FTIR characterization was performed in attenuated total reflection (ATR) mode on all PEEK and PEKK products. A Nicolet 6700 instrument from Thermo Scientific was used. The spectra are the results of 16 recordings with a resolution of $4 \mathrm{~cm}^{-1}$. The results have been normalized by using the absorption band at $1599 \mathrm{~cm}^{-1}$ as a reference, which corresponds to elongation of aromatic $\mathrm{C}=\mathrm{C}$ bond.

\subsubsection{Thermogravimetric analysis}

TGA characterization was performed on all PEEK and PEKK products and PET. Approximately $16 \mathrm{mg}$ of each sample was first held at $100^{\circ} \mathrm{C}$ for $15 \mathrm{~min}$, and then heated to $800^{\circ} \mathrm{C}$ at a heating rate of $10 \mathrm{~K} \mathrm{~min}^{-1}$, under argon.

\subsubsection{Differential scanning calorimetry}

DSC characterization was performed on all raw products, stitching yarns and composite combinations. Calorimetry measurements were performed with a Mettler Toledo DSC1. For all experiments, aluminum sealed pans filled with $7 \mathrm{mg} \pm 1 \mathrm{mg}$ of the products were used. The samples were subjected to four heating and cooling cycles, the first one was applied to erase the thermal history. The applied treatment consisted in heating the sample at $20^{\circ} \mathrm{C}$ $\mathrm{min}^{-1}$, then in holding it at 400 or $380^{\circ} \mathrm{C}$ during 5 and $20 \mathrm{~min}$ to cause degradation ( $5 \mathrm{~min}$ for the first cycle and 20 for the other periods), and finally in cooling it at a constant rate of $10^{\circ} \mathrm{C} \mathrm{min}{ }^{-1}$ to induce polymers crystallization in identical conditions. During this last stage of the thermal treatment, the crystallization temperature $\left(T_{c}\right)$ was measured. $T_{c}$ was taken as the maximum of the crystallization peak.

\subsubsection{Rheometry}

Rheometry characterization was performed on all raw products and composite combinations. For rheological measurements all the samples were prepared with the same method. Filaments were initially ground using a Retsch ultra centrifugal mill ZM 100 with a $0.5 \mathrm{~mm}$ sieve. The mill was cooled with liquid nitrogen to avoid overheating. Then the powders were compacted with a force of $29 \mathrm{kN}$ during 1 min using an Instron press 5567 and a cylindrical die with a diameter of $20 \mathrm{~mm}$. The obtained samples were consolidated using a thermocompression pilot plant equipped with the 3iTech technology from Roctool. The thermo-compression cycle applied consisted in a heating phase at $42^{\circ} \mathrm{C} \mathrm{min}^{-1}$, an isothermal stage of $3 \mathrm{~min}$ just above the melting temperature under a force of $125 \mathrm{kN}$, and finally in a cooling stage at $50^{\circ} \mathrm{C} \mathrm{min}{ }^{-1}$. Rheological measurements were performed on these consolidated samples with a Mars Haake rheometer using a plate-plate geometry in oscillatory mode with disposable alumina plates of a diameter of $20 \mathrm{~mm}$. During the experiments, constant shear and shear rates respectively of 0.01 and $6.28 \mathrm{~s}^{-1}$ $(1 \mathrm{~Hz})$ were applied, at $400^{\circ} \mathrm{C}$. In order to guarantee the linear viscoelastic domain, strain sweep tests were first performed so that the complex viscosity could be simply determined from the elastic and viscous moduli $G^{\prime}$ and $\mathrm{G}^{\prime \prime}$. 


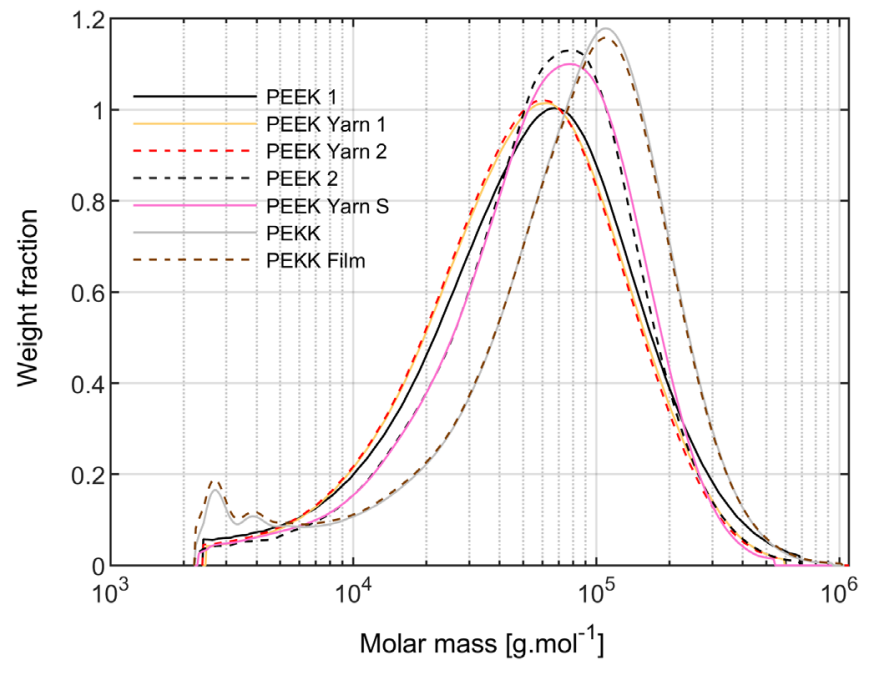

FIG URE 1 Comparison of the molecular weight distributions of PEEK and PEKK matrices with raw polymers [Color figure can be viewed at wileyonlinelibrary.com]

\section{RESULTS}

\subsection{Initial state}

\subsubsection{Molecular weight}

Figure 1 displays the molecular weight distributions of PEEK and PEKK matrices of the different preforms as well as those of the corresponding raw materials. The related average molecular weights $M_{n}$ and $M_{w}$ and polydispersity index $I_{p}$ are summarized in Table 2. The GPC results clearly show the difference between the two generations of PEEK Victrex 150. Compared to PEEK 1, the second generation of PEEK 150, that is PEEK 2, exhibits a higher average molecular weight but a narrower molecular weights distribution.

The processing of PEEK 1 into yarns results in lower $M_{n}, M_{w}$, and $I_{p}$ parameters, with a significant decrease of the weight average molecular weight $M_{w}$ of about $8000 \mathrm{~g}$ mol $^{-1}$ for both PEEK Yarn 1 and PEEK Yarn 2. This change of molecular weight values is due to a diminution of the proportion of longer molecules of high-molecular weight and consequently to an increase of shorter molecules proportion. As opposed to PEEK 1-based materials, the extrusion of PEEK 2 into PEEK yarns did not modify significantly the molecular weight. $M_{n}$ and $M_{w}$ only decreased of about 300 and $500 \mathrm{~g} \mathrm{~mol}^{-1}$ respectively (Table 2) and only a slight evolution of higher weight molecules is visible in Figure 1.

The GPC results then confirm that the melt spinning process can induce chain scissions and a reduction of molecular weight parameters as it has been observed for other polymers. ${ }^{18,19,20}$ However, this effect is not so prominent for
TABLE 2 Average molecular weights and polydispersity index of PEEK and PEKK grades

\begin{tabular}{|c|c|c|c|}
\hline Reference & $M_{n}\left(\mathrm{~g} \mathrm{~mol}^{-1}\right)$ & $M_{w}\left(\mathrm{~g} \mathrm{~mol}^{-1}\right)$ & Ip \\
\hline PEEK 1 & 30,291 & 82,097 & 2.7 \\
\hline PEEK Yarn 1 & 30,198 & 74,273 & 2.5 \\
\hline PEEK Yarn 2 & 29,392 & 72,433 & 2.5 \\
\hline PEEK 2 & 34,381 & 82,111 & 2.4 \\
\hline PEEK Yarn S & 34,062 & 81,583 & 2.4 \\
\hline PEKK & 32,668 & 108,067 & 3.3 \\
\hline PEKK Film & 30,363 & 107,165 & 3.5 \\
\hline
\end{tabular}

the second generation of PEEK Victrex 150 although it is composed of longer molecules. The processing conditions used for yarn manufacturing can explain such difference, but it is also likely that some stabilizing agent were added in this second PEEK generation. ${ }^{38}$

The molecular weight distribution of PEKK reference is significantly different to that of PEEK references with a $M_{w}$ of $108000 \mathrm{~g} \mathrm{~mol}^{-1}$ and a polydispersity index $I_{p}$ of 3.3. This PEKK grade is also particular in that it exhibits a multimodal distribution with large proportions of oligomers of 2500 and $4000 \mathrm{~g} \mathrm{~mol}^{-1}$. This PEKK grade is thus probably prepared by combining together different populations of PEKK of different molecular weights. The transformation into film did not affect the global shape of the molecular weight distribution of PEKK. The PEKK Film does have a lower $M_{n}$ and a higher $I_{p}$ in comparison with the raw PEKK grade but also an unchanged proportion of high-molecular weight molecules after processing. This combination of data then suggests that no chain scissions occurred during the extrusion processing. The difference of $M_{n}$ and $I_{p}$ of the PEKK materials then could be due to a slight variability in the ratio of chain populations used to prepare the PEKK grade.

\subsubsection{Fourier transform infrared spectroscopy}

The FTIR spectroscopy is commonly used for analyzing the chemical modifications induced by the thermal degradation of PEEK and PEKK. ${ }^{25,39,24}$ The most obvious changes observed on PEEK absorption spectra after heat treatment are the appearance of new absorption bands in the carbonyl band between 1700 and $1800 \mathrm{~cm}^{-1}$ and in the hydroxyl zone between 3400 and $3700 \mathrm{~cm}^{-1}$. These absorption bands are attributed to the elongation vibration of $\mathrm{C}-\mathrm{O}$ bonds of benzoic anhydride $\left(1780 \mathrm{~cm}^{-1}\right)$, phenyl benzoate $\left(1739 \mathrm{~cm}^{-1}\right)$ and fluorenone $\left(1711 \mathrm{~cm}^{-1}\right)$, and to the elongation vibration of $\mathrm{O}-\mathrm{H}$ bonds of phenols and all 


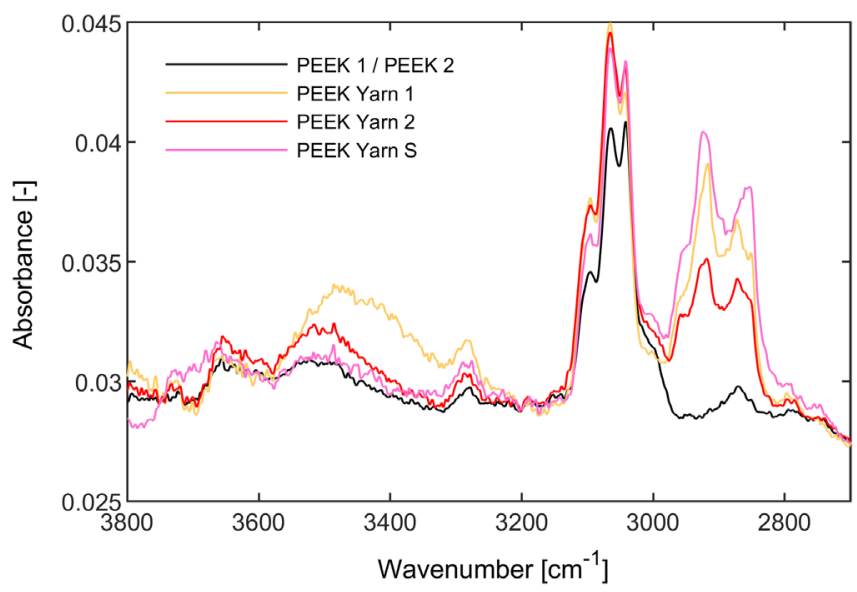

F I G U RE 2 FTIR spectra of PEEK and PEEK yarns showing the apparition of new absorption bands at $2850 \mathrm{~cm}^{-1}$ and $2935 \mathrm{~cm}^{-1}$-PEEK 1 and PEEK 2 have identical spectra. FTIR, Fourier transform infrared spectroscopy [Color figure can be viewed at wileyonlinelibrary.com]

other types of hydroxyl products, mostly benzoic acid respectively.

In the present study, the analysis of those specific absorption bands did not reveal any particular difference between the PEEK and PEKK matrices and the raw materials. All spectra of same materials are well superimposed. Therefore, no evidence of thermal degradation could be demonstrated by FTIR spectroscopy although little modifications of molecular weight were detected. In particular, the FTIR absorption spectra of raw PEKK and PEKK Film are almost perfectly superimposed, which confirms that the PEKK Film does not contain any additional additives compared to raw PEKK or surface treatment.

In studies using FTIR spectroscopy for investigating the thermal degradation of PAEK, the degradation procedures are defined so as to amplify the level of degradation and the resulting chemical changes. Severe heat treatments from hours and up to several months are generally applied. In their study of the thermal degradation of PEEK at the rubbery state for instance, Courvoisier et al. ${ }^{24}$ exposed PEEK films to $250^{\circ} \mathrm{C}$ during $10,000 \mathrm{~h}$. As for the studies dealing with the thermal degradation beyond the melting temperature, the applied heat treatments generally last several hours or at the very least a few minutes. ${ }^{23,28}$ It is therefore not surprising that no significant change in absorption bands was detected for the PEKK Film and the PEEK yarns.

The only significant difference between the different materials is the appearance of absorption bands in the range from 2800 to $3000 \mathrm{~cm}^{-1}$ for all materials containing additives. As shown in Figure 2, two new absorption bands appear at 2850 and $2935 \mathrm{~cm}^{-1}$ for all PEEK yarns.

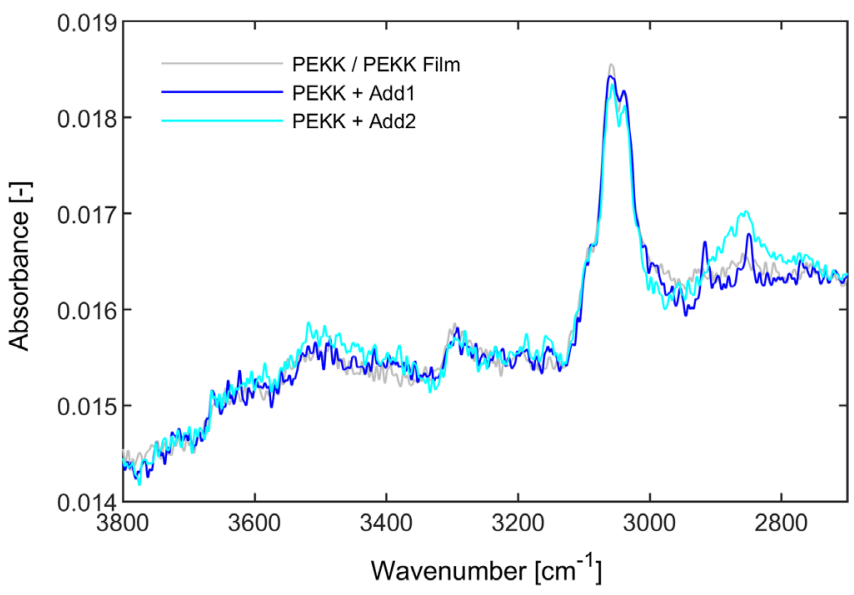

F I G U RE 3 FTIR spectra of PEKK products showing additional absorption bands at $2850 \mathrm{~cm}^{-1}$ and $2935 \mathrm{~cm}^{-1}$-PEKK and PEKK film have identical spectra. FTIR, Fourier transform infrared spectroscopy [Color figure can be viewed at wileyonlinelibrary.com]

These bands, that correspond to aliphatic $\mathrm{C}-\mathrm{H}$ bonds, ${ }^{31}$ are the signature of the sizing agent at the surface of PEEK yarns. Regarding PEKK suspensions, a similar modification in the aliphatic region is observed in presence of suspension additives. In the case of PEKK+Add1, it is characterized by the same absorption bands at 2850 and $2935 \mathrm{~cm}^{-1}$ while a more diffuse absorption band is obtained in the case of PEKK+Add2 (Figure 3).

The chemical characterization of PAEK matrices by means of chromatography and FTIR spectroscopy techniques finally indicates that film and yarn extrusion of PAEK has limited consequences on the molecular structure of the polymers. However, given the usual residence time in an extruder, it is likely that the degradation process had been activated during the extrusion operation with the formation of primary radicals. Therefore, an effect of the extrusion step on the subsequent consolidation of composite preforms cannot be completely ruled out. Indeed, the changes in the hydroxyl region ( 3300 $-3600 \mathrm{~cm}^{-1}$ ) could be related to the formation of primary radicals and phenols.

\subsection{Degradation behavior}

In order to assess the influence of matrix form on the subsequent preform consolidation, the matrices were analyzed by means of TGA, calorimetry and rheology techniques. The experiments were performed on the matrix isolated from the carbon reinforcement. This made it possible to compare the properties of the matrix with the raw materials, which is not possible when considering the preform itself. It also permitted to neglect 


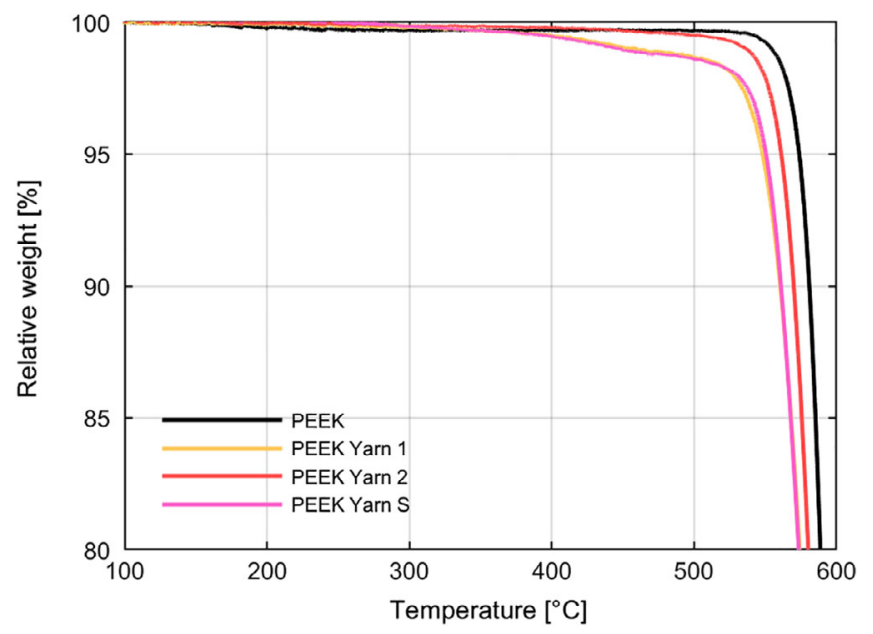

F I G U RE 4 TGA weight loss for PEEK products recorded during a heating ramp of $10^{\circ} \mathrm{C} \mathrm{min}^{-1}$. TGA, thermogravimetric analysis [Color figure can be viewed at wileyonlinelibrary.com]

the influence of carbon fibers and in particular their sizing that are not identical for all preforms. The three techniques were used to characterize the thermal stability of the preform matrices, and the degradation kinetics were compared to raw PEEK and PEKK behaviors. Differences appearing during thermal treatments were then analyzed so as to get evidence of the influence of preform preparation on composite properties.

\subsubsection{Degradation of PEEK yarns}

Thermogravimetric experiments were performed in nonisothermal conditions at $10^{\circ} \mathrm{C} \mathrm{min}^{-1}$ under argon. As shown in Figure 4, the kinetics of mass loss of raw PEEK samples (PEEK 1 and PEEK 2 curves overlap perfectly) is extremely limited up to $500^{\circ} \mathrm{C}$. The weight loss starts from $520^{\circ} \mathrm{C}$ and a maximum kinetics around $570^{\circ} \mathrm{C}$ is observed. This phase of intense degradation is associated with the breakdown of the chemical bonds between the ether functions and the aromatic ring or ketone rings and aromatic rings. ${ }^{40}$ PEEK yarns exhibit kinetics characterized by a rapid mass loss at high temperature too, but inflection points appear at lower temperature, indicating the existence of chemical modifications within the material before this intense mass loss. For the PEEK Yarn 2, a gradual loss of mass occurs from $400^{\circ} \mathrm{C}$ before accelerating sharply above $550^{\circ} \mathrm{C}$. For PEEK Yarn 1 and PEEK Yarn $\mathrm{S}$, the mass loss starts earlier from $300^{\circ} \mathrm{C}$ and an inflection point around $430^{\circ} \mathrm{C}$ is visible. This indicates that a particular mechanism has been activated. The degradation then accelerates similarly to PEEK Yarn 2 and PEEK references beyond $500^{\circ} \mathrm{C}$.
TABLE 3 Temperature related to a weight loss of 5\% for PEEK products

\begin{tabular}{|l|l|}
\hline Sample & Temperature at 5\% of weight loss \\
\hline PEEK 1/PEEK 2 & 574 \\
\hline PEEK Yarn 1 & 549 \\
\hline PEEK Yarn 2 & 561 \\
\hline PEKK & 564 \\
\hline PEKK+Add1 & 562 \\
\hline PEKK+Add2 & 554 \\
\hline PEKK Film & 564 \\
\hline PEEK Yarn S & 550 \\
\hline PET Yarn S & 397 \\
\hline
\end{tabular}

The differences observed between the materials cannot be explained by the sole effect of the yarn extrusion processing. Indeed, the molar mass distributions of PEEK Yarn 1 and PEEK Yarn 2 are perfectly identical (Figure 1) while their degradation behavior is significantly different. Moreover, raw PEEK materials have a perfectly identical mass loss kinetics but distinct molar masses. These results then prove that the mass loss behavior upon heating is directly related to the chemical nature of the materials more than to the molecular weight.

In the case of PEEK Yarn 1, the yarns were covered with an epoxy-based sizing agent right after the hot drawing step, while for PEEK Yarn 2, it is an ester-based sizing containing poly-ethylene-glycol (PEG). The sizing ratios are $0.45 \%$ and $0.27 \%$ respectively for PEEK Yarn 1 and PEEK Yarn 2. The early stage of mass losses appearing between 300 and $450^{\circ} \mathrm{C}$ is therefore linked to the loss of volatiles formed during sizing degradation. Denault et al. actually observed an identical phenomenon with carbon fibers. ${ }^{16}$ They measured a mass loss of about $0.5 \%$ between 300 and $400^{\circ} \mathrm{C}$ that corresponded to the weight ratio of carbon fiber sizing.

However, contrary to carbon yarns, the mass loss of PEEK yarns at $450^{\circ} \mathrm{C}$ is slightly higher than the sizing ratios, which indicates that the sizing degradation simultaneously induced the formation of volatile species resulting from chemical modifications of the PEEK yarns. This synergy between the sizing products and the matrix is confirmed by the temperature recorded for $5 \%$ of mass loss (Table 3). The analysis of the temperatures in Table 3 shows that a low thermal stability of the sizing leads to a decrease in the temperature for which a $5 \%$ mass loss is observed. Nevertheless, even if the sizing ratio and the thermal stability may have a significant influence on the thermogravimetric results, the sizing nature may also 


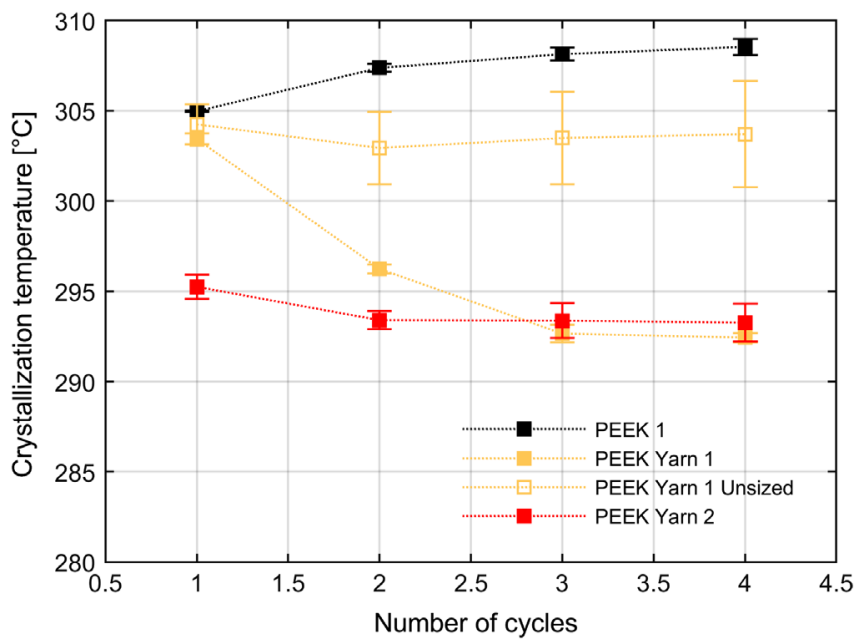

F I G U RE 5 Change of PEEK crystallization temperature after exposure periods at $400^{\circ} \mathrm{C}$ [Color figure can be viewed at wileyonlinelibrary.com]

affect this classification and the intensification of PEEK degradation.

Calorimetric parameters are commonly used to assess the final performances of the composite material after preform consolidation. In the case of PEKK, for instance, Choupin et al. clearly demonstrated that the mechanical performances of this polymer are directly related to its crystallinity. ${ }^{41}$ The crystallinity is also an indicator of the level of degradation: the Young modulus, the yield stress and the crystallinity drastically decrease with the level of degradation.

Thermal cycling in DSC was carried out for PEEK 1, PEEK Yarn 1, and PEEK Yarn 2 at $400^{\circ} \mathrm{C}$, this temperature corresponding to a conventional processing condition for this material. The crystallization temperature $\left(T_{c}\right)$ was recorded during the cooling phases of each melting/crystallization cycle (Figure 5). Phase change temperature was preferred rather than the degree of crystallinity as its identification does not require any integration procedure and is therefore less variable. The choice was also made in this study to focus on the $T_{c}$ rather than on the melting temperature $T_{m}$ because the crystallization is not disturbed by the melting-crystallization process that occurs upon heating. ${ }^{42}$ The evolution of the $T_{c}$ has already been used in the literature by Day et al. and Pascual et al. to monitor the evolutions of PAEK stability. ${ }^{43,28}$ Though, the melting temperature $T_{m}$ is more often used in the literature. ${ }^{34,24,32}$

The Figure 5 shows that the $T_{c}$ of PEEK increases slightly after each heat treatment at $400^{\circ} \mathrm{C}$, while the crystallization temperature of PEEK Yarn 1 and PEEK Yarn 2 decreases after each cycle. The decrease of $T_{c}$ is associated with the crosslinking process which reduces the mobility of macromolecules and therefore the crystallization ability. This has been demonstrated by several authors, especially Day et al. ${ }^{43}$ and Jonas et al. ${ }^{26}$ who analyzed the cold crystallization of PEEK after heat treatment and liquid nitrogen quenching. However, the slight increase in the $T_{c}$ of PEEK 1 is here different from the literature. The fact that crystallization was achieved from the melt state may explain this divergence from the literature, but chain breakage, that is one of the elementary mechanisms of PEEK degradation in a neutral environment, is the most probable mechanism for explaining such trend.

For all the other materials tested in this study, thermal cycling systematically resulted in a decrease in the crystallization temperature. In the case of PEEK Yarn 1 , the first measured $T_{c}$ is of the same order as that of PEEK 1, around $305^{\circ} \mathrm{C}$, but the $T_{c}$ then gradually decreases until representing after 4 cycles a drop of more than $10^{\circ} \mathrm{C}$. The $T_{c}$ of PEEK Yarn 2 is from the first cycle almost $10^{\circ} \mathrm{C}$ lower than that of PEEK 1 . On the other hand, its decrease with the number of cycles is much smaller: between the 1 st and the 4 th cycle, the $T_{c}$ only evolved by $2^{\circ} \mathrm{C}$. The lower crystallization temperature PEEK Yarn 2 from the first isothermal plateau of $5 \mathrm{~min}$ at $400^{\circ} \mathrm{C}$ is likely to be due to an initial degradation during the extrusion operation. Indeed, its $M_{n}$ and $M_{w}$ are slightly lower than PEEK Yarn 1 . The gradual decrease of $T_{c}$ therefore demonstrates that the epoxy-based sizing of PEEK Yarn 1 increases PEEK degradation kinetics in the DSC environment, whereas the sizing of PEEK Yarn 2 (PEG) has a low effect on PEEK crystallization. The DSC results then confirm the first conclusions drawn with TGA results.

In Figure 5 are also reported results obtained on unsized fibers from PEEK Yarn 1. These results were obtained on fibers immersed in an acetone bath and treated for 1 hour in an ultrasonic tank. This treatment allowed removing all or part of the sizing deposited on the yarns after extrusion. The same procedure was carried out on the PEEK Yarn 2 fibers but the DSC and rheology results did not show any difference compared to the sized PEEK Yarn 2. It is probable that the acetone treatment was not effective in removing the PEG-based sizing and the results are therefore not presented here. After de-sizing, the decrease in the $T_{c}$ of PEEK Yarn 1 was significantly reduced which confirms that the sizing products are responsible for an acceleration of the thermal degradation of PEEK.

The Figure 6 compares the viscous behavior at $400^{\circ} \mathrm{C}$ of PEEK Yarn 1 and PEEK Yarn 2 with that of PEEK 1. For each material, the experiments were performed under argon flow and in air environment in order to analyze the thermal and thermo-oxidative degradation 

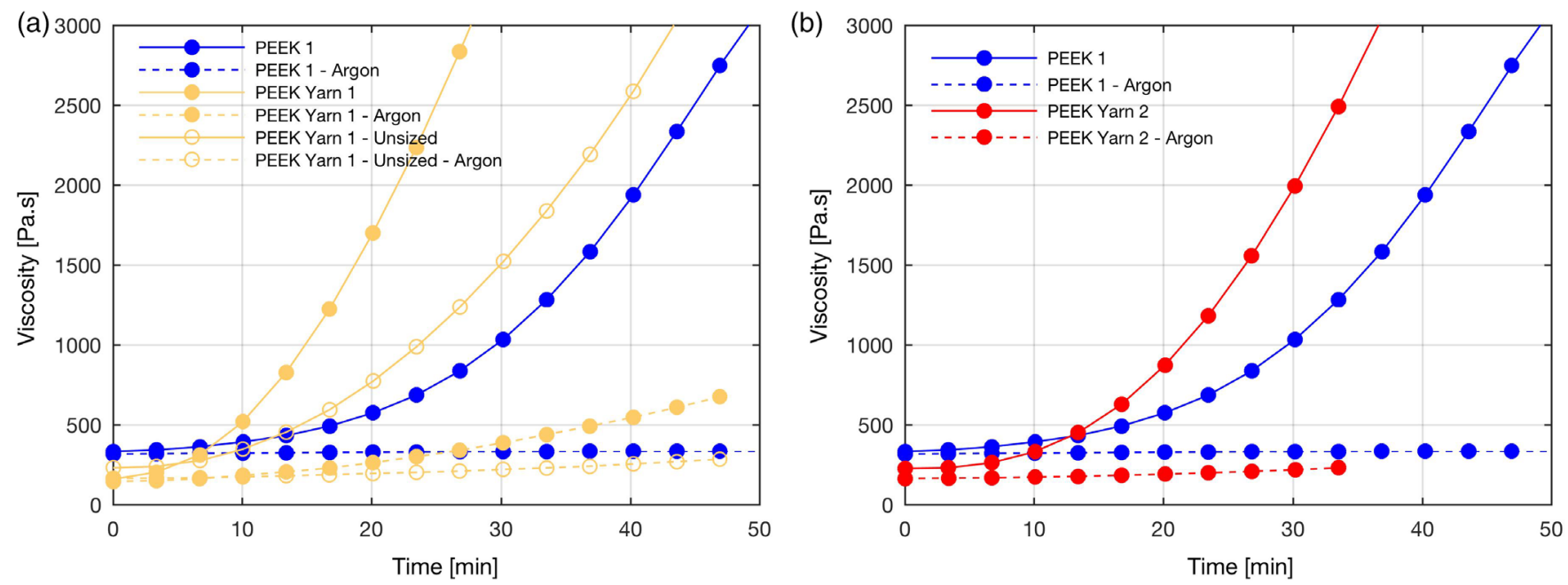

F I G U RE 6 Time evolution of the viscosity of PEEK products at $400^{\circ} \mathrm{C}$ [Color figure can be viewed at wileyonlinelibrary.com]

processes. In neutral environment, the integrity of PEEK 1 is preserved throughout the duration of the test. This rheological test condition then does not show evidence of chain breakage or recombination of radicals. Conversely, the oxidative environment induces an exponential increase of PEEK 1 viscosity: the level of viscosity if multiplied by a factor 5 within $40 \mathrm{~min}$. This change of viscosity is a consequence of crosslinking as already reported by several authors. ${ }^{34,31,44,32}$

Both PEEK Yarn 1 and PEEK Yarn 2 exhibit an initial viscosity that is lower than the raw material, no matter whether they were tested in air or argon atmosphere. This can be due to the lower $M_{w}$ of yarn references according to Mark-Houwink equation, but also to a lubricating effect of the sizing that is generally composed of low-molar mass aliphatic molecules. In air condition, the viscosity of PEEK Yarn 1 and PEEK Yarn 2 then increases due to the crosslinking process, but more rapidly than PEEK 1. This degradation is substantially slowed down under argon flow but unlike PEEK, the slight increase in viscosity over time indicates that molecular changes still occur despite the absence of oxygen.

The tests carried out on the unsized PEEK Yarn 1 show a significant drop in the degradation kinetics in air and under argon compared to the same sized reference. In particular in air, the viscosity increases rapidly but with a kinetics barely greater than that of PEEK 1. This result again proves that the sizing has a critical effect on the degradation kinetics of PEEK 1 by playing the role of catalyst.

The rheological study finally shows that the epoxybased sizing of PEEK Yarn 1 has a stronger interaction with PEEK during degradation than PEEK Yarn 2, which is consistent with the results of TGA and DSC analysis. Nevertheless, even if the periphery of the $20 \mathrm{~mm}$ diameter samples degrades according to a thermooxidative process, the degradation kinetics may be different in samples core depending of the oxygen diffusion coefficient. The degradation of these massive samples then may vary as a function of sample diameter and rheological data may result from the combination of different chemical processes.

\subsubsection{Degradation of PEKK suspension for slurry powder impregnation}

The experiments on PEKK suspensions were performed on dried suspensions that contain only the PEKK powder and the additives among which surfactants. Therefore, contrary to the other preforms, the initial state of thermogravimetric, calorimetric and rheological data does not correspond to the actual pre-impregnated preform state but to an intermediate state. For the fabrication of pre-impregnated ribbons, after the slurry impregnation of carbon ribbons, the soaked carbon/PEKK systems still need to be heated above the melting temperature and calendered. The melting stage required for the preparation of pre-impregnated ribbons may thus affect the preform behavior.

The Figure 7 compares the thermogravimetric behavior of PEKK with that of PEKK+Add1 and PEKK+Add2 suspensions. As for PEEK, PEKK is very stable over a wide range of temperature and exhibits only intense mass loss in TGA at high temperature. The intense mass loss occurs from $480^{\circ} \mathrm{C}$ and the temperature corresponding to a $5 \%$ mass loss is $564^{\circ} \mathrm{C}$, that is, $10^{\circ} \mathrm{C}$ lower than PEEK 1 (Table 3).

The TGA curve of PEKK+Add1 is very close to that of PEKK, with a temperature corresponding to a 5\% mass 


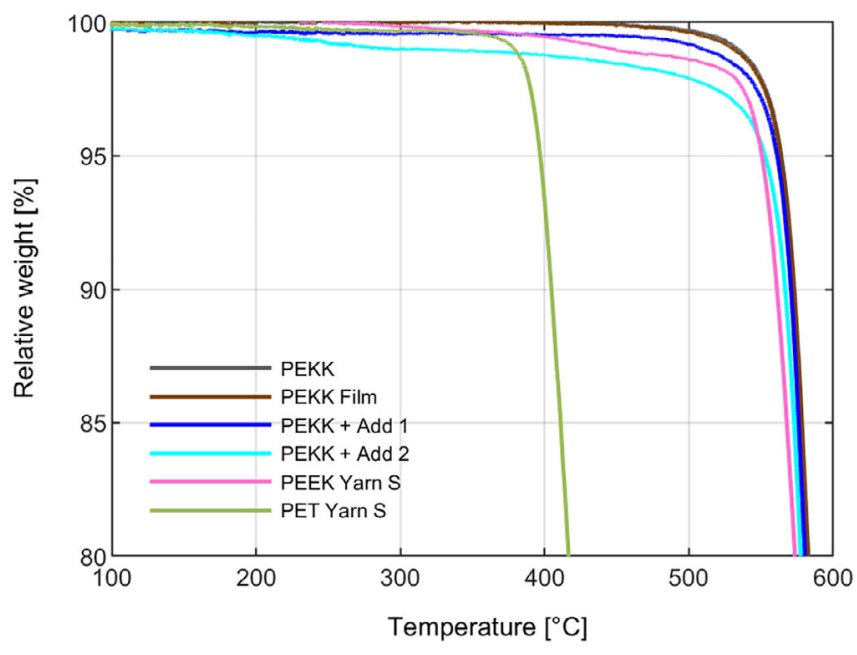

F I G URE 7 TGA weight loss for PEKK recorded during a heating ramp of $10^{\circ} \mathrm{C} \mathrm{min}^{-1}$. TGA, thermogravimetric analysis [Color figure can be viewed at wileyonlinelibrary.com]

loss of $562^{\circ} \mathrm{C}$. PEKK+Add 2 exhibits a first phase of mass loss between 200 and $280^{\circ} \mathrm{C}$ and then a second intense loss at high temperature. In PEKK+Add2 suspension, nearly $1 \%$ of the mass of the sample is lost from $300^{\circ} \mathrm{C}$, which corresponds to the mass rate of the additive 2 in the PEKK matrix. The 5\% mass loss is obtained for a temperature of $554^{\circ} \mathrm{C}$, that is, $10^{\circ} \mathrm{C}$ lower than pure PEKK. The additive 2 is therefore responsible for accelerating the degradation of PEKK.

The additive 1 is only composed of a surfactant that is stable in temperature. TGA tests carried out in air at $5^{\circ} \mathrm{C}$ $\mathrm{min}^{-1}$ indicate an intense loss of mass at $480^{\circ} \mathrm{C}$. The mass loss of PEKK+Add1 is therefore not affected by the presence of this additive. Conversely, the additive 2 is composed of an oil and two surfactants which decompose at $5^{\circ} \mathrm{C} \mathrm{min}{ }^{-1}$ in air at 310,280 , and $340^{\circ} \mathrm{C}$ respectively. The most probable assumption is that the degradation of additives molecules acts as catalysts for the thermal degradation of PEKK.

The importance of additives thermal stability on PEKK degradation kinetics is also noticeable on DSC and rheometry data. As shown in Figure 8, the raw PEKK powder shows a very slight drop in the $T_{c}$ after each heat treatment at $380^{\circ} \mathrm{C}$ in DSC. The total variation is only $2^{\circ} \mathrm{C}$ after four cycles. This evolution of the $T_{c}$ is in agreement with the results of Choupin et al. ${ }^{32}$ who observed a delayed isothermal crystallization with the level of degradation due to crosslinking.

Regarding the viscous behavior in air at $380^{\circ} \mathrm{C}$, an increase in viscosity is observable for raw PEKK (Figure 9). However, the increase of PEKK viscosity is linear rather than exponential. This difference of degradation kinetics between PEEK and PEKK is directly correlated to the

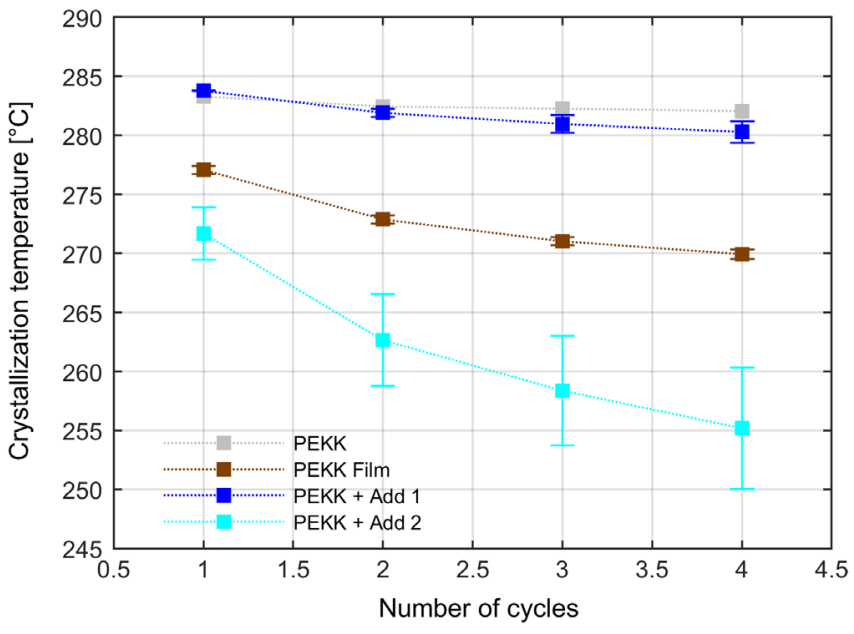

F I G U RE 8 Change of the crystallization temperature of PEKK products after exposure periods at $380^{\circ} \mathrm{C}$ [Color figure can be viewed at wileyonlinelibrary.com]

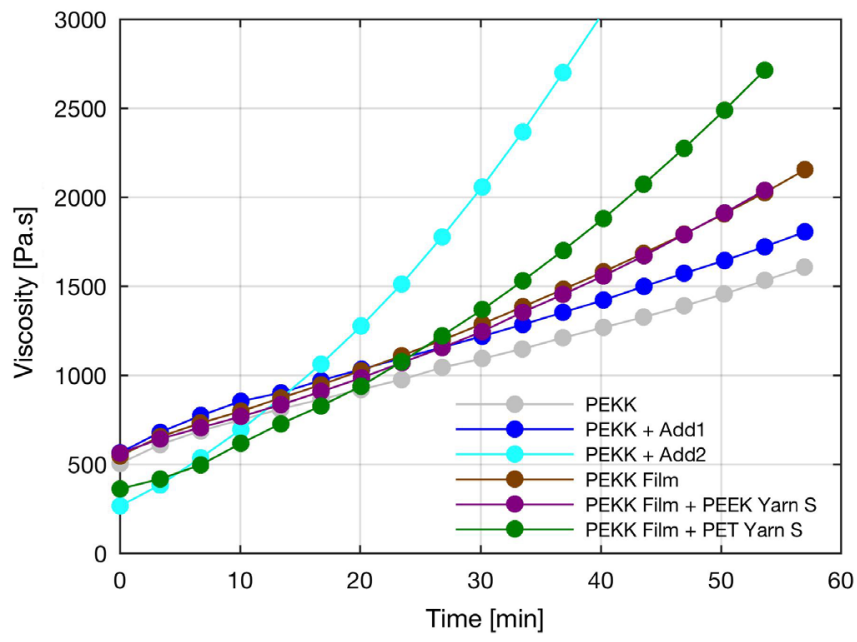

F I G U RE 9 Time evolution of the viscosity of PEKK products at $380^{\circ} \mathrm{C}$ [Color figure can be viewed at wileyonlinelibrary.com]

thermal stability of the ether and ketone groups. As demonstrated by Abate et al., ${ }^{45}$ ketone groups are more stable than ether groups. PEKK is thus inherently more stable than PEEK because of a higher ketones to ether ratio. Moreover, the initial viscosity of PEKK is only slightly higher than that of PEEK 1 although its molar mass is significantly higher. This is due to the large proportion of PEKK chains of low-molar mass in this PEKK grade, as shown in Figure 1. Although PEKK initial viscosity is higher than that of PEEK at $t=0$, its viscosity after $40 \mathrm{~min}$ is lower than that of PEEK 1.

With the addition of a stable surfactant (Add1), the degradation kinetic of PEKK is barely affected. Only a small decrease of $2^{\circ} \mathrm{C}$ of the $T_{c}$ is observed for PEKK+Add1, after the four cycles at $380^{\circ} \mathrm{C}$, and a difference in the viscosity of 
only 100 Pa.s is obtained after $55 \mathrm{~min}$ at $380^{\circ} \mathrm{C}$. On the contrary, PEKK+Add2 have a completely different behavior. Its $T_{c}$ is approximately $10^{\circ} \mathrm{C}$ lower than that of PEKK after only $5 \mathrm{~min}$ at $380^{\circ} \mathrm{C}$ and this difference increases over the cycles until representing $28^{\circ} \mathrm{C}$ after the four heat treatments in DSC. A drastic effect of the additives in PEKK+Add2 is also visible on the viscous behavior. Like in the case of PEEK yarns, the initial viscosity of PEKK+Add2 is lower than that of PEKK because of the presence of oil in the formulation of the additive 2 , the oil having a lubricating/plasticizing effect. The crosslinking kinetics is however considerably increased in the presence of the two surfactants and the oil involved in PEKK+Add2 suspension. The interaction of PEKK with the by-products of additives degradation results in an exponential increase of PEKK+Add2 viscosity: after $40 \mathrm{~min}$, the viscosity is twice higher than that of raw PEKK.

These results therefore show that the degradation of PEKK can be affected by the presence of additives, but that the presence of additives is not necessarily a factor accelerating the chemical modifications. In the case of PEKK+Add1, the integrity of the PEKK matrix is preserved by the fact that the surfactant involved in this suspension has a degradation temperature higher than the isotherm level of the heat treatment.

\subsubsection{Degradation of PEKK films and stitching yarns}

The properties of the NCF preform were assessed by analyzing the interaction of PEKK Film with the stitching yarns using the same experimental procedure as for the

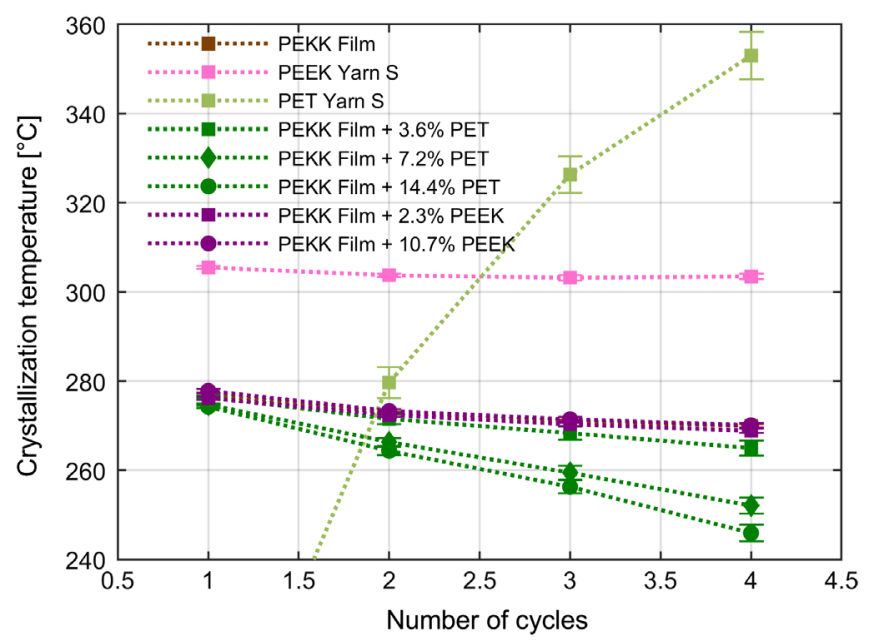

F I G URE 10 Influence of the rate and nature of the stitching yarn on the change of PEKK crystallization temperature after exposure periods at $380^{\circ} \mathrm{C}$ [Color figure can be viewed at wileyonlinelibrary.com]
PEEK materials and PEKK suspensions. The influence of film extrusion on the integrity of the PEKK matrix was first analyzed. Then, the stitching yarns were analyzed separately so as to analyzed the influence of stitching yarn nature on the thermal behavior of PEKK matrix.

The Figure 7 shows that the thermal degradation of PEKK and PEKK Film are identical. The temperatures associated with $5 \%$ mass loss are the same for both materials. A difference in the crystallization behavior however appears in Figure 8. The transformation of PEKK into film results in a significant decrease in the crystallization temperature $T_{c}$ (approximately $6^{\circ} \mathrm{C}$ ). The $T_{c}$ progressively evolves during thermal cycles at $380^{\circ} \mathrm{C}$ with a total decrease of about $7^{\circ} \mathrm{C}$ after 4 cycles, which corresponds to a final difference with raw PEKK of about $12^{\circ} \mathrm{C}$. Regarding the viscous behavior, both the PEKK Film and raw PEKK have the same initial viscosity, but the PEKK Film degrades with a slightly higher kinetics. However, although the extrusion transformation has a distinct effect on PEKK degradation kinetics, its contribution remains limited. The viscosity increase that can be attributed to extrusion is only $250 \mathrm{~Pa} . \mathrm{s}$ after $50 \mathrm{~min}$ at $380^{\circ} \mathrm{C}$ whereas the degradation of raw PEKK results in an increase of 1000 Pa.s.

Concerning the stitching yarns, as already mentioned, the TGA curves of PEEK Yarn S and PEEK Yarn 1 that are displayed in Figure 4 are very close. The sizing of PEEK Yarn S decomposes between 400 and $450^{\circ} \mathrm{C}$ and the degradation by-products induce an acceleration of the thermal degradation of PEEK matrix. Because of their identical thermogravimetric behavior, PEEK Yarn $\mathrm{S}$ is expected to behave like PEEK Yarn 1, that is, with limited thermal stability. However, in the NCF preform, PEEK Yarn $\mathrm{S}$ is not used as the main matrix material but as a stitching yarn. The temperature to which it is exposed depends on the processing temperature of the PEKK matrix, and the heat treatment experiments in DSC were thus performed on PEEK Yarn S at $380^{\circ} \mathrm{C}$. The DSC results finally show that PEEK Yarn $S$ is perfectly stable after the four heat treatment stages at this temperature (Figure 10). The range of $20^{\circ} \mathrm{C}$ between 380 and $400^{\circ} \mathrm{C}$ then corresponds to a transition zone for PEEK stability.

On the contrary, PET is a semi-aromatic polyester and has therefore a lower thermal stability compared to aromatic PEEK and PEKK. The PET Yarn S rapidly degrades when exposed to high temperature: $5 \%$ mass loss was recorded at only $397^{\circ} \mathrm{C}$ (Table 3 ), which is just above the processing temperature of PEKK. The significant increase in its $T_{c}$ after heat treatments at $380^{\circ} \mathrm{C}$ provides indisputable proof of molecular modifications: the $T_{c}$ of PET increases from $184^{\circ} \mathrm{C}$ to $353^{\circ} \mathrm{C}$ after 4 thermal cycles at $380^{\circ} \mathrm{C} \mathrm{min}^{-1}$. 
In order to analyze further the properties of the NCF preform, rheology samples were prepared by mixing PEKK Film material with 3.6\% of PET Yarns S and with $2.3 \%$ of PEEK Yarn S. These proportions correspond to the actual weight ratios of the corresponding stitching yarn used for assembling the carbon plies with the PEKK films. As shown in Figure 9, the addition of PEEK did not modify the viscous behavior of PEKK Film, while the addition of $3.6 \%$ of PET Yarn S changed both the initial viscosity of the PEKK mixture and the related crosslinking kinetics. The mobility of the aliphatic sections of PET unit can explain the lower initial viscosity, but the faster degradation process necessarily results from the degradation of PET macromolecules.

Despite the fact that chemical modifications in PET occur quickly at $380^{\circ} \mathrm{C}$, it does not induce a major change in the degradation behavior. The addition of $3.6 \%$ of PET Yarn $\mathrm{S}$ changed the crystallization temperature of about $10^{\circ} \mathrm{C}$, which is lower than in the case of PEKK+Add2.

Results obtained for higher ratios of stitching yarn are also presented in Figure 10. They confirm that the stability of PEEK allows preserving the integrity of the PEKK Film material, while the increase of PET ratio amplifies the degradation kinetics of PEKK Film. If a ratio of 3.6\% of PET Yarn S only lowers the PEKK $T_{c}$ of about $3^{\circ} \mathrm{C}$ after four cycles, a ratio of $14.4 \%$ affects the $T_{c}$ of PEKK Film by $23^{\circ} \mathrm{C}$.

\section{DISCUSSION}

Whatever the type of preform, PEEK and PEKK matrices always degrade according to the process of chain breakage and crosslinking described by many authors. ${ }^{25,23,21,24}$ The same evidence of the degradation process as reported in the literature has been observed such as the decrease in decomposition temperature by TGA, ${ }^{9,31,28}$ the decrease in crystallization temperature ${ }^{43,28}$ or the increase in viscosity. ${ }^{31,44,32,34}$ The comparison of semi-finished products of different architectures indicates that the transformation of the matrix into yarn or film as well as the presence of additives have an effect on the thermal stability of PAEK. It mainly affects the kinetics of the degradation process but the consequences on the material properties remains similar.

The results obtained on PEEK yarns and PEKK films confirm that the extrusion step influences the properties of the matrix. Melt spinning extrusion causes a distinct change in the molecular weight distribution of PEEK and in particular in the proportion of high-molecular weight macromolecules. The consequences of extrusion on thermal and thermo-oxidative degradation are, however, limited. The properties of the de-sized PEEK Yarn 1 and
PEKK Film are indeed very close to those of the corresponding PEEK and PEKK raw materials. PEKK and PEKK Film have actually very similar molecular weights and TGA behavior. The fact that the film extrusion does not require the application of high-melt drawing rates is probably the reason for this stability.

Even if the extrusion processing leads to a modification of the stability of the PAEK matrices, the results obtained by the different characterization techniques demonstrate unambiguously that the organic materials with which PAEK matrices are in contact are a determining factor of their thermal and thermo-oxidative degradation. The most pronounced consequences were obtained in the case of PEKK+Add2 and in the case of commingled preforms, that is, PEEK Yarn 1 and PEEK Yarn 2. The presence of the PEKK+Add2 additives and the PEEK yarns sizing results in a clear acceleration of the degradation kinetics. In the case of PEEK Yarn 1, for example, the increase in viscosity is so rapid that after only $20 \mathrm{~min}$ it reaches a level three times higher than that of the pure matrix. Similarly, PEKK+Add2 has a crystallization temperature almost $25^{\circ} \mathrm{C}$ lower than that of raw PEKK.

The degradation data collected from the impregnation suspensions also reveal that this synergy with the matrices mainly occurs when the additives degrade. While the surfactant used as an additive in the PEKK+Add1 suspension only slightly affects the behavior of PEKK, the additives in PEKK+Add2 clearly affect its degradation kinetics due to their low thermal stability. Likewise, PEEK Yarn S, which is stable at $380^{\circ} \mathrm{C}$, has only a very slight effect on the behavior of PEKK, whereas the PET stitching yarn causes a significant change in the behavior of the matrix.

However, the nature and proportion of organic additives in contact with PAEK matrices remain a determining factor in the degradation kinetics of matrices. The decomposition of PET, for instance, which occurs at low temperatures due to its semi-aromatic nature, affects the degradation kinetics of PEKK less than the additives in PEKK+Add2. The $1 \%$ wt rate of surfactants and oil in PEKK+Add2 is sufficient to lower the $T_{c}$ of PEKK by $25^{\circ} \mathrm{C}$ whereas a rate of $14 \%$ wt of PET is necessary to obtain a comparable effect.

This study thus demonstrates that the preparation of composite preforms should not only be considered from an architectural point of view when they are prepared with PAEK matrices. While an optimal matrix distribution within the textile reinforcements improves the impregnation in the case of low-melting point matrices, it may be completely different in the case of high-performance thermoplastic matrices. Their high processing temperature makes them inherently sensitive to thermal degradation, and the multiplication of processing operations before 
final consolidation of the composite parts can alter the final composite properties.

This is all the more true since the preparation of complex preforms requires the use of complementary products such as sizing or surfactants. Particular attention must be paid to the selection of these products in contact with PAEK matrices as they can have considerable effects on the properties of the final preform, and ultimately may negate the benefits of complex architecture. The thermal stability of the additive products is a crucial element: the decomposition of the materials surrounding the PAEK matrices results in the formation of by-products like radicals, hydroxyls that interfere with the chemical reactions of the PAEK degradation process. This synergy with PEAK is therefore directly related to the nature and rate of the additives, both being determining factors on the degradation kinetics of PAEK.

Even so, additives like oil can in some cases act as matrix plasticizers and initially reduce the viscosity of the system. This property of the additives can then be beneficial for impregnation and facilitate the consolidation of the composites. However, if their thermal stability is limited, they can induce accelerated degradation of the PAEK matrix after a certain time and then produce the opposite effect. The time required for consolidating the preforms is thus a decisive factor.

\section{CONCLUSIONS}

The comparison of matrices from various preforms allowed highlighting the effect of preform preparation on the integrity of the matrix. It appeared that whatever the form of the matrix in the composite preforms, the matrix still degrades according to the crosslinking process described in literature. The comparative study demonstrated that the preform manufacturing is responsible for an acceleration of the degradation kinetics of PAEK at the molten state.

However, more than yarn or film extrusion processes, a significant modification of PAEK degradation kinetics was generated by the organic products in contact with PAEK. This effect is particularly pronounced when the additives and other secondary products decompose at a lower temperature than the processing temperature of the matrix. Because of this synergetic effect with the PAEK matrices, all the surrounding products must be selected with care. A misselection of these products can hinder the benefit of preparing complex preforms and induce a significant loss of preforms processability.

In order to go further in the understanding of composite preforms behavior, a thorough investigation of the carbon sizing should be performed. The characterization of the by-products formed during additives decomposition may also give a new insight about the degradation kinetics of PAEK polymers.

\section{ACKNOWLEDGMENTS}

The authors wish to thank the IFTH for their support in the characterization of yarn sizings and the Region Occitanie for their financial support.

\section{ORCID}

Olivier De Almeida (1) https://orcid.org/0000-0002-4875-

8713

\section{REFERENCES}

[1] M. Péron, F. Jacquemin, P. Casari, G. Orange, J.-L. Bailleul, N. Boyard, J. Compos. Mater. 2019, 53, 3169-.arXiv.

[2] A. Luisier, P. E. Bourban, J.-A. E. Månson, J. Appl. Polym. Sci. 2001, 81, 963.

[3] C. Vicard, O. De Almeida, A. Cantarel, G. Bernhart, Polymer 2017, 132, 88.

[4] P. E. Bourban, N. Bernet, J. E. Zanetto, J. A. E. Månson, Compos. - Part A Appl. Sci. Manuf. 2001, 32, 1045.

[5] C. V. Katsiropoulos, S. G. Pantelakis, B. C. Meyer, Theor. Appl. Fract. Mech. 2009, 52, 122.

[6] S. T. Jespersen, M. D. Wakeman, V. Michaud, D. Cramer, J. A. Månson, Compos. Sci. Technol. 2008, 68, 1822.

[7] L. Ye, K. Friedrich, J. Mater. Process. Technol. 1995, 48, 317.

[8] M. D. Wakeman, T. A. Cain, C. D. Rudd, R. Brooks, A. C. Long, Compos. Sci. Technol. 1999, 59, 709.

[9] Z. Xu, M. Zhang, S. H. Gao, G. Wang, S. Zhang, J. Luan, Polym. Compos. 2019, 40, 56.

[10] D. F. Hiscock, D. M. Bigg, Polym. Compos. 1989, 10, 145.

[11] L. Tang, L. Li, X. Yi, Z. Pan, Polym. Compos. 1997, 18, 223.

[12] G. M. Wu, J. M. Schultz, Polym. Compos. 2000, 21, 223.

[13] X. Wang, C. Mayer, M. Neitzel, Polym. Compos. 1997, 18, 701.

[14] P. Nygård, C. G. Gustafson, J. Thermoplast. Compos. Mater. 2004, 17, 167.

[15] T. Hartness, G. Husman, J. Koenig, J. Dyksterhouse, Compos. Part A Appl. Sci. Manuf. 2001, 32, 1155.

[16] J. Denault, T. Vu-Khanh, Polym. Compos. 1992, 13, 361.

[17] S. Kazano, T. Osada, S. Kobayashi, K. Goto, Mech. Adv. Mater. Mod. Process. 2018, 4, 1.

[18] K. H. Lee, S. J. Lim, W. N. Kim, Macromol. Res. 2014, 22, 624.

[19] J. Shojaeiarani, D. S. Bajwa, C. Rehovsky, S. G. Bajwa, G. Vahidi, Polymer 2019, 11, 1.

[20] M. R. Milana, M. Denaro, L. Arrivabene, A. Maggio, L. Gramiccioni, Food Addit. Contam. 1998, 15, 355.

[21] J. N. Hay, D. J. Kemmish, Polymer 1987, 28, 2047.

[22] M. Day, J. D. Cooney, D. M. Wiles, J. Appl. Polym. Sci. 1989, 38, 323.

[23] M. Day, D. Sally, D. M. Wiles, D. Chemistry, J. Appl. Polym. Sci. 1990, 40, 1615.

[24] E. Courvoisier, Y. Bicaba, X. Colin, Polym. Degrad. Stab. 2018, 151, 65.

[25] K. C. Cole, I. G. Casella, Thermochim. Acta 1992, 211, 209.

[26] A. Jonas, R. Legras, Polymer 1991, 32(15), 2691.

[27] P. Patel, T. R. Hull, R. W. McCabe, D. Flath, J. Grasmeder, M. Percy, Polym. Degrad. Stab. 2010, 95, 709. 
[28] A. Pascual, M. Toma, P. Tsotra, M. C. Grob, Polym. Degrad. Stab. 2019, 165, 161.

[29] M. Day, J. D. Cooney, D. M. Wiles, J. Anal. Appl. Pyrolysis 1990, 18, 163.

[30] K. L. White, L. Jin, N. Ferrer, M. Wong, T. Bremner, H. J. Sue, Polym. Eng. Sci. 2013, 53, 651.

[31] V. Mylläri, T. P. Ruoko, J. Vuorinen, H. Lemmetyinen, Polym. Degrad. Stab. 2015, 120, 419.

[32] T. Choupin, B. Fayolle, G. Régnier, C. Paris, J. Cinquin, B. Brulé, Polym. Degrad. Stab. 2018, 155, 103.

[33] M. Coulson, L. Quiroga Cortés, E. Dantras, A. Lonjon, C. Lacabanne, J. Appl. Polym. Sci. 2018, 135, 46456.

[34] R. Phillips, T. Glauser, J. A. E. Månson, Polym. Compos. 1997, 18,500 .

[35] G. Le, F. Sguerra, Method for impregnating reinforcing fibres with polyaryletherketones and semi-finished products obtained in this way, Worldwide Patent WO2019053379A1 (march 2019).

[36] A. Texier, R. M. Davis, K. R. Lyon, A. Gungor, J. E. McGrath, H. Marand, J. S. Riffle, Polymer 1993, 34, 896.

[37] D. Coudeyre, B. Defoort, M. Destarac, S. Franceschi, K. Labastie, A. Malho Rodrigues, E. Perez, Aqueous thermoplastic-polymer dispersion, and use of same for the impregnation of reinforcing fibres, Worldwide Patent WO2019102141A1 (may 2019).

[38] G. Le, P. Bussi, Method for stabilising a composition made from poly(aryl-ether-ketone) (paek), Worldwide Patent WO2017013369A1 (january 2017).
[39] S. Giancaterina, A. Rossi, A. Rivaton, J. Gardette, Polym. Degrad. Stab. 2000, 68, 133.

[40] G. Rival, T. Paulmier, E. Dantras, Polym. Degrad. Stab. 2019, 168, 108943.

[41] T. Choupin, L. Debertrand, B. Fayolle, G. Régnier, C. Paris, J. Cinquin, B. Brulé, Polym. Cryst. 2019, $2,1$.

[42] X. Tardif, B. Pignon, N. Boyard, J. W. Schmelzer, V. Sobotka, D. Delaunay, C. Schick, Polym. Test. 2014, 36, 10.

[43] M. Day, T. Suprunchuk, J. D. Cooney, D. M. Wiles, J. Appl. Polym. Sci. 1988, 36, 1097.

[44] M. I. Martín, F. Rodríguez-Lence, A. Güemes, A. FernándezLópez, L. A. Pérez-Maqueda, A. Perejón, Compos. Part A: Appl. Sci. Manuf. 2018, 111, 23.

[45] L. Abate, I. Blanco, A. Orestano, A. Pollicino, A. Recca, Polym. Degrad. Stab. 2003, 80, 333. 